\title{
Critical condition study of borehole stability during air drilling
}

\author{
Deng Jingen ${ }^{1 *}$, Zou Linzhan ${ }^{1}$, Tan Qiang', Yan Wei ${ }^{1}$, Gao Deli ${ }^{1}$, \\ Zhang Hanlin ${ }^{2}$ and Yan Xiuliang ${ }^{3}$
}

\author{
${ }^{1}$ MOE Key Laboratory of Petroleum Engineering, China University of Petroleum, Beijing 102249, China \\ ${ }^{2}$ Drilling Research Institute of Changqing Oilfield, Xi'an, Shaanxi 710048, China \\ ${ }^{3}$ Drilling Research Institute of Shengli Oilfield, Dongying, Shandong 257100, China
}

\begin{abstract}
The purpose of this paper is to establish the existence of the critical condition of borehole stability during air drilling. Rock Failure Process Analysis Code ${ }^{2 \mathrm{D}}$ was used to set up a damage model of the borehole excavated in strain-softening rock. Damage evolution around the borehole was studied by tracking acoustic emission. The study indicates that excavation damaged zone (EDZ) is formed around borehole because of stress concentration after the borehole is excavated. There is a critical condition for borehole stability; the borehole will collapse when the critical damage condition is reached. The critical condition of underground excavation exists not only in elastic and ideal plastic material but in strainsoftening material as well. The research is helpful to developing an evaluation method of borehole stability during air drilling.
\end{abstract}

Key words: Borehole stability, air drilling, critical condition

\section{Introduction}

In recent years, air drilling has become an important technology in the oil and gas industry. No liquid column pressure is applied to the downhole rock during air drilling, so the rate of penetration (ROP) can be greatly increased. However, air drilling is confronted with such problems as water layer prediction, evaluation of borehole stability, and destabilization of borehole wall after switching to drilling with mud. This paper focuses on borehole stability during air drilling. Compared with other underground excavation, air drilling has such features as: (1) Deep formation with a depth of 500-5,000 m; (2) The diameter of borehole is from $8-1 / 2^{\prime \prime}$ to $12-1 / 4^{\prime \prime}$; (3) Cuttings are lifted out of the wellbore by gases, instead of the conventionally used liquids; (4) There is almost no support on borehole wall. A damaged or plastic zone around the borehole is inevitably created. Is there a critical condition of borehole stability during air drilling? It is important to answer this question for safe air drilling.

The elastic solution to excavation of spherical or cylindrical cavities in a hydrostatically loaded medium is given by Lamé's solution (Jaeger and Cook, 1976). The elasto-plastic solution can be simplified as a quasi-static problem, not related to constitutive equation (Salençon, 1969; Wang et al, 1982). Usually, this problem should be solved based on incremental analysis taking constitutive equation into account (Carranza-Torres, 1998; Carranza-Torres and Fairhurst, 1999). Owing to the assumption of ideal elasto-

*Corresponding author. email: Dengjg@bjpeu.edu.cn; dengjingen@126.com Received December 18, 2008 plastic behavior, the critical plastic condition of borehole stability can not be determined according to the solution.

The critical condition of engineering structure can be obtained in an independent way through the application of theorems of the limit analysis (upper bound or lower bound) (Chen, 1975; Drucker and Prager, 1952; Durand et al, 2006). However, the limit analysis theorems also assume that the plastic behavior of the material is perfect or ideally plastic, i.e., the yield surface is fixed in the stress space, which results in over-estimating the stability of the rock structure. In fact, under most engineering conditions, in which neither the temperature nor the hydrostatic pressure is too high, the rock shows strain-softening properties other than ideal plasticity. So the plastic zone cannot keep stable expansion as predicted by elasto-plastic analysis (Carranza-Torres, 1998; CarranzaTorres and Fairhurst, 1999), and there is a critical condition before destabilization (Xu and Liu, 1995).

In fact phenomenological strain-softening and nonlinearity of rock can be reasonably explained by rock damage mechanics. As micro-cracks initiate and propagate on the small scale and combine into macro-fractures, the strength and stiffness of rock deteriorate (Wawersik and Brace, 1971; Steif, 1984; Sammis and Ashby, 1986; Martin and Chandler, 1994). Micromechanical fracture models are proposed to describe non-linear rock deformation (Costin, 1985; Singh and Digby, 1989; Hommand-Etienne et al, 1998; Eberhardt et al, 1999). The acoustic emission (AE) method is proved to be valuable for monitoring microcracking and damage process (Alcott et al, 1998; Hardy, 2003; Cai et al, 2007).

In this paper, a Rock Failure Process Analysis Code called RFPA ${ }^{2 D}$ (Tang, 1997; Tang and Kaiser,1998a; 1998b; 
Tang et al, 2000; Wang et al, 2004; Zhang et al, 2006; Zhu and Tang, 2006) was used here to study the critical damage condition of borehole excavation during air drilling. RFPA ${ }^{2 D}$ is based on an elastic damage model that can deal with both tensile damage and shear damage at the meso-element level. In the following sections, a brief introduction to RFPA ${ }^{2 D}$ will be presented first, followed by numerical simulation using RFPA $^{2 \mathrm{D}}$ to examine the critical damage condition. Furthermore true triaxial tests in laboratory were carried out to verify the results of numerical simulation.

\section{Brief outline of RFPA ${ }^{2 \mathrm{D}}$}

RFPA $^{2 D}$ (Tang, 1997) employs some peculiar computational techniques and processing methods and it has the following special features: (1) by introducing rock heterogeneity into the model, RFPA $^{2 \mathrm{D}}$ can simulate nonlinear deformation of a quasi-brittle rock with an ideal brittle constitutive law for local material; (2) by introducing a reduction in material parameters after element failure, RFPA $^{2 D}$ can simulate continuum mechanics mode; (3) by recording the event-rate of failed elements, RFPA $^{2 \mathrm{D}}$ can simulate seismicities associated with progressive fracture process.

For the heterogeneity of rock-like materials, the properties such as uniaxial compressive strength and elastic modulus for elements are randomly distributed throughout the specimen by following the Weibull distribution:

$$
\varphi(\alpha)=\frac{m}{a_{0}}\left(\frac{a}{a_{0}}\right)^{m-1} \exp \left[-\left(\frac{a}{a_{0}}\right)^{m}\right]
$$

where $\alpha$ is the element parameter; $\alpha_{0}$ is the mean value of the element parameter for the specimen; and $m$ is the shape parameter, which is defined as the homogeneity index of the rock (Tsang et al, 2005). Fig. 1 shows the distribution shape of element mechanical property with different homogeneity indices.

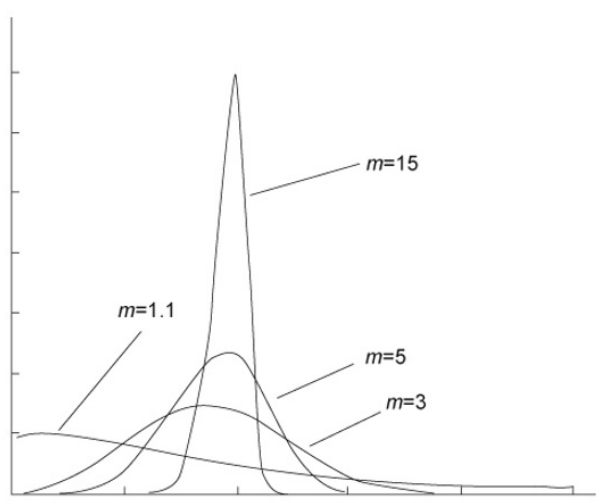

Fig. 1 Distribution shape of element mechanical property with different homogeneity indices

In elastic damage mechanics, the elastic modulus of the element may degrade gradually as damage progresses, and the elastic module of damaged material is defined as follows:

$$
E=(1-D) E_{0}
$$

where $D$ represents the damage variable; $E$ and $E_{0}$ are the elastic modulus of the damaged and the undamaged elements, respectively. Here the element and its damage are assumed to be isotropic elastic. Therefore, $E, E_{0}$ and $D$ are all scalar.

The elastic damage constitutive relations for an element under uniaxial compressive stress and tensile stress are illustrated in Fig. 2.

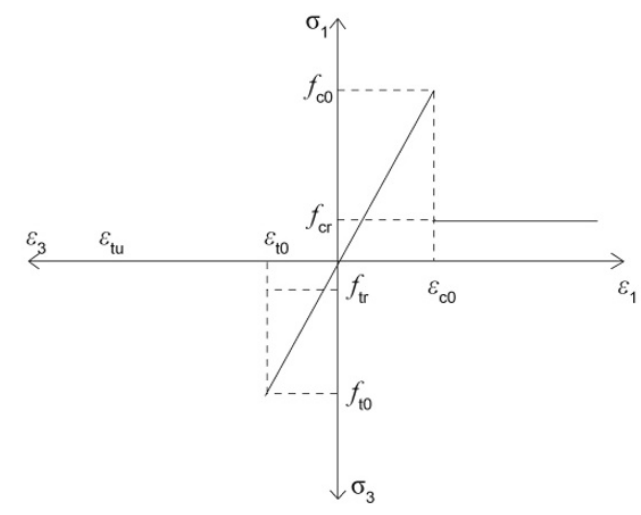

Fig. 2 Mesoscopic elemental constitutive relations under uniaxial compressive stress and tensile stress

To describe the element damage under the compressive or shear stress condition, the Mohr-Coulomb method is chosen to be the damage criterion, which can be described as follows:

$$
F=\sigma_{1}-\sigma_{3} \times \frac{1+\sin \varphi}{1-\sin \varphi} \geq f_{\mathrm{c}}
$$

where $\varphi$ is the internal friction angle; $f_{\mathrm{c}}$ is the uniaxial compressive strength; $\sigma_{1}$ and $\sigma_{3}$ are the major and minor principal stress, respectively.

When the stress condition of element meets the MohrCoulomb criterion, shear damage occurs and the damage variable $D$ can be described as follows:

$$
D=\left\{\begin{array}{cc}
0 & \varepsilon<\varepsilon_{\mathrm{c} 0} \\
1-\frac{f_{\mathrm{cr}}}{E_{0} \varepsilon} & \varepsilon \geq \varepsilon_{\mathrm{c} 0}
\end{array}\right.
$$

where $f_{\text {cr }}$ is the residual compressive strength.

\section{Numerical tests}

Here, a practical rock medium was presented, it was a complete stress-stain curve and acoustic emission features were obtained by numerical uniaxial strength test. The model's material properties were assigned in accordance with the uniaxial test. The critical condition was studied by numerical tests. Also damage features were compared under hydrostatic loading and non-hydrostatic loading.

\subsection{Geometric model}

The radius of the hole is small compared with the length of the cylinder so that plane-strain conditions are applicable (Fig. 3). The in-situ stress has an initial value of magnitude of $5 \mathrm{MPa}$ before the borehole is excavated, and then increases step by step after borehole excavation. The pressure inside the borehole may be neglected in the case of air drilling. The boundary is situated at a distance of ten times of borehole diameter from the axis of the borehole. 


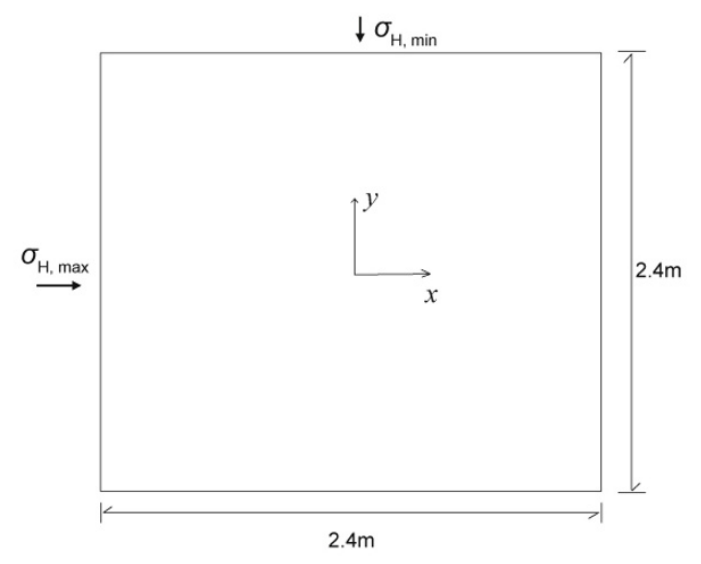

(a) Before borehole excavation

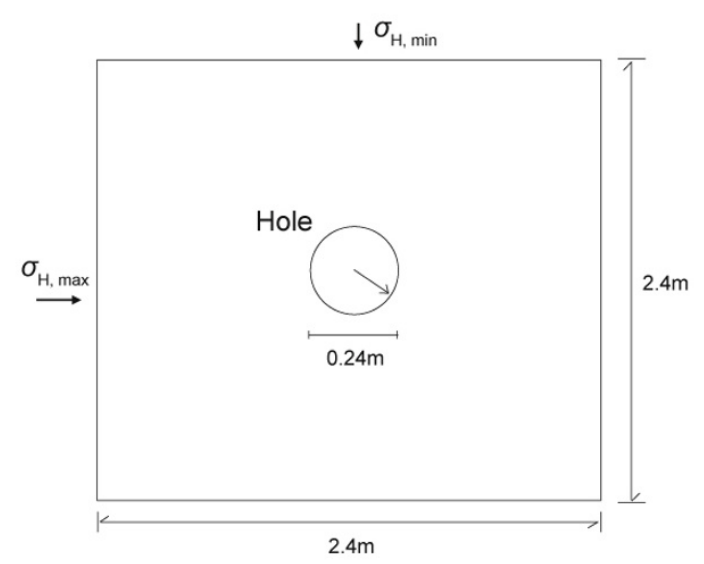

(b) After borehole excavation

Fig. 3 Geometric model

\subsection{Material properties}

In fact, rock exhibits strain softening after the peak load is reached in uniaxial compression. Here, the properties of rock material are listed in Table 1.

Table 1 Material properties

\begin{tabular}{cccc}
\hline $\begin{array}{c}\text { Uniaxial compressive } \\
\text { strength, MPa }\end{array}$ & $\begin{array}{c}\text { Friction } \\
\text { angle, }\end{array}$ & $\begin{array}{c}\text { Elastic } \\
\text { modulus, MPa }\end{array}$ & $\begin{array}{c}\text { Poisson's } \\
\text { ratio }\end{array}$ \\
\hline 25 & 30 & 6000 & 0.25 \\
\hline
\end{tabular}

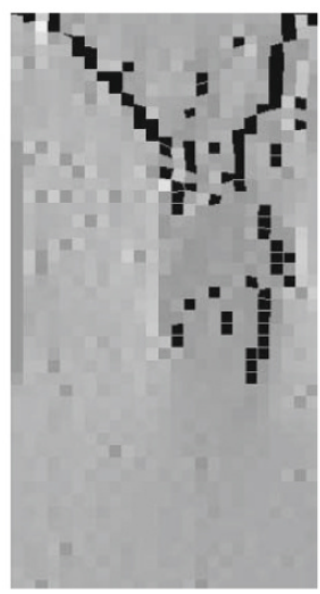

(a) Test specimen
Fig. 4 shows the uniaxial compression test of the rock, including the test specimen, complete stress-strain curve, and acoustic emission counts. After peak strength, stress descends sharply from $25 \mathrm{MPa}$ down to $6 \mathrm{MPa}$.

\subsection{In-situ stress path}

To study the critical condition, the stress path is set as follows: first, the in-situ stress has an initial magnitude of 5 $\mathrm{MPa}$ before the borehole is excavated and the in-situ stress increases step by step after the borehole is excavated. Fig. 5 shows the in-situ stress path. The pressure inside the borehole may be neglected for air drilling, so it is set to zero.

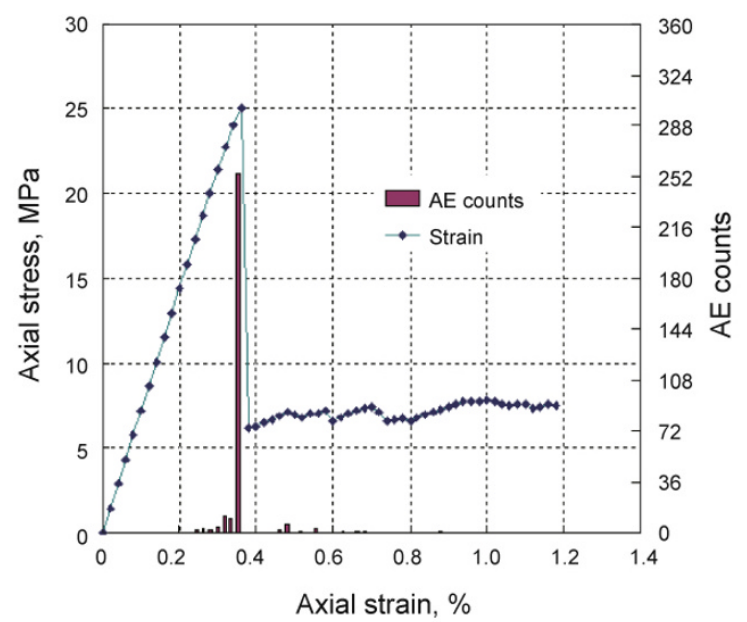

(b) Stress-strain curve and AE counts

Fig. 4 Uniaxial compression test of the rock

\subsection{Numerical simulation of borehole excavation}

\section{1) Critical damage condition of bore-hole excavation} under hydrostatic loading

The numerical result shows that a critical condition of borehole stability exists. The in situ stress increases step by step on the boundary after the borehole is excavated. No pressure exists in the borehole, rock surrounding the borehole starts to damage from the inner wall when in-situ stress exceeds the elastic limit. The damaged zone advances gradually with increasing in-situ stress. Once the critical condition is reached, the in-situ stress keeps unchanged and the damaged zone expands unstably until the model collapsed completely. The in-situ stress equals twice the elastic limit under the critical condition.

Fig. 6 shows that stress concentrates mostly on the inner wall of the borehole under elastic limit condition and less acoustic emission occurs.

When the in-situ stress increases beyond the elastic limit load, a plastic zone emerges and expands around the borehole. In the beginning, acoustic emissions are created by shear 
damage, and tensile acoustic emissions will also emerge at the place where shear acoustic emissions converge, indicating formation of macro-cracks.

Fig. 7 shows stress and damage under the critical condition. Under the critical condition, if the in-situ stress on the boundary continues to increase, the damaged zone expands unstably till the model collapses completely. This process is shown in Fig. 8. The result shows that a critical damage condition exists for borehole stability, and the corresponding in-situ stress is the limiting stress that the borehole can bear. Once the in-situ stress exceeds the ultimate bearing capacity, the damaged zone will expand to 10 times of borehole radius or more, resulting in instability of borehole.

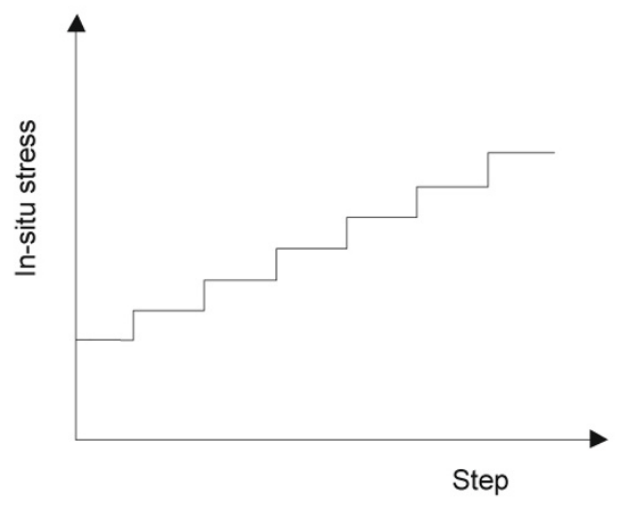

Fig. 5 Sketch of the in situ stress path

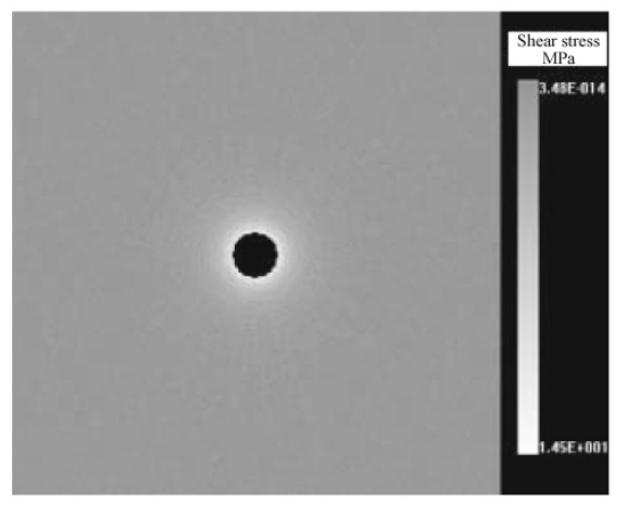

(a) Shear stress around borehole

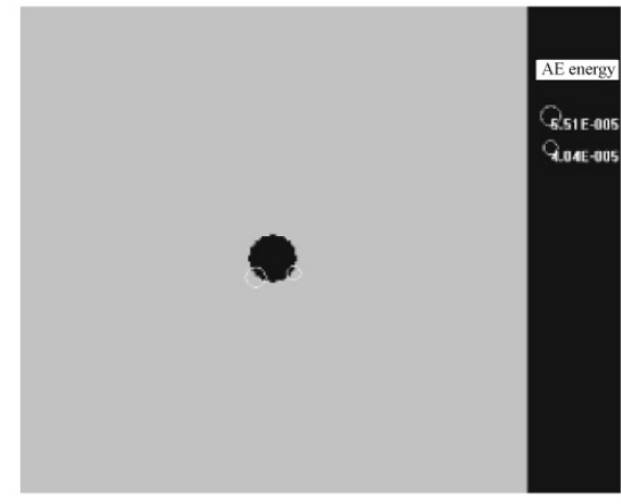

(b) AE around borehole

Fig. 6 Elastic limit condition in Step 4

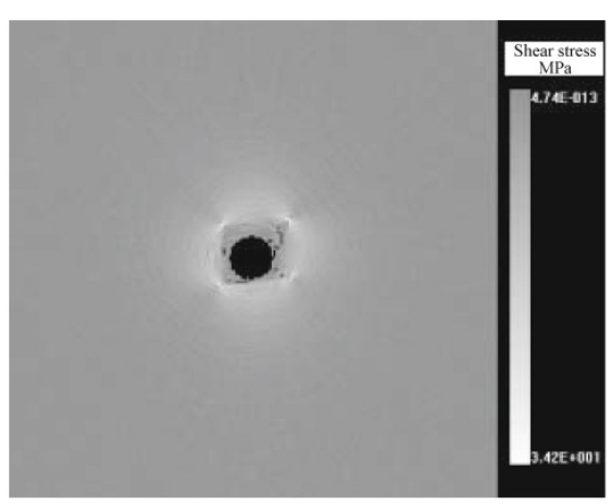

(a) Shear stress around borehole

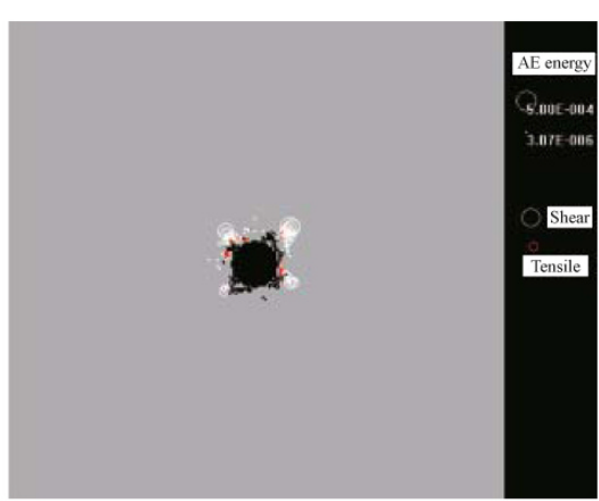

(b) AE around borehole

Fig. 7 Critical condition of borehole stability in Step 8
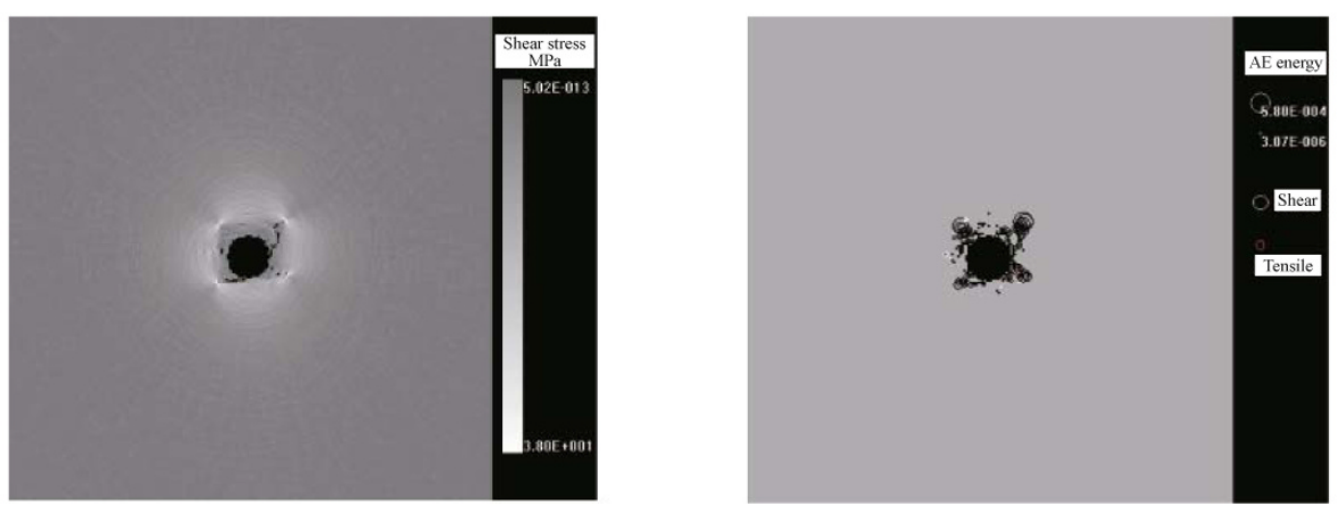

(a) Sub Step 1 of Step 9 

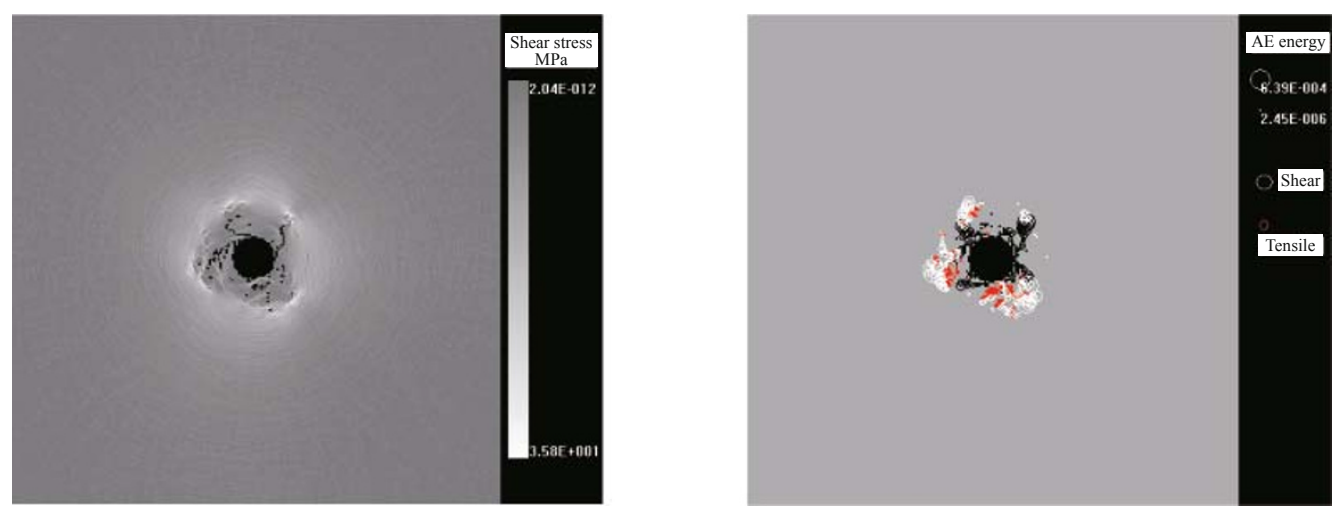

(b) Sub Step 10 of Step 9
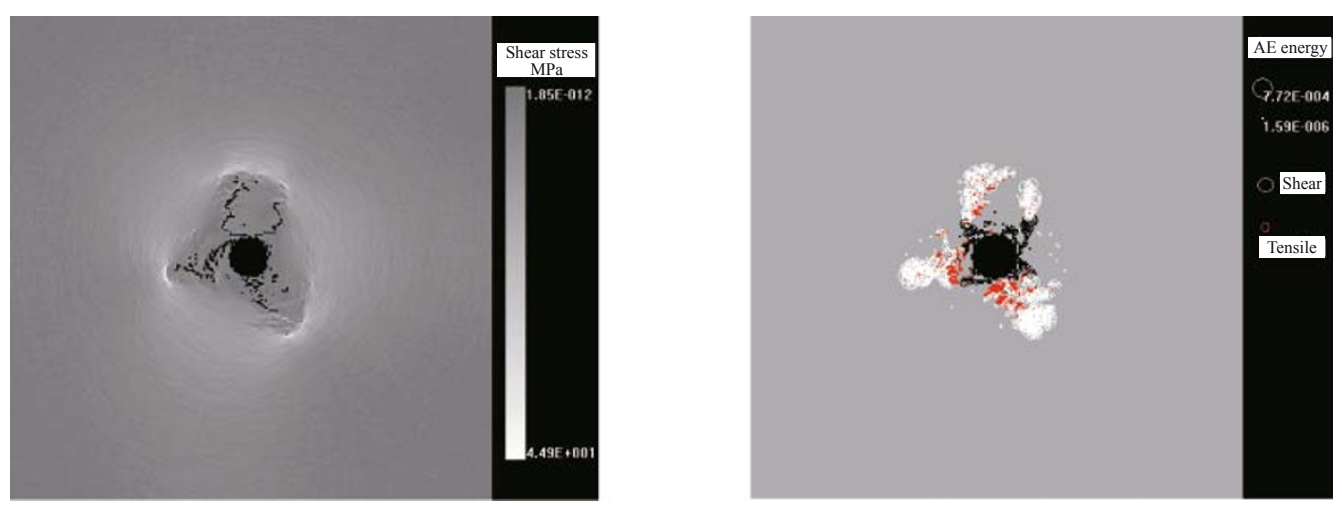

(c) Sub Step 20 of Step 9
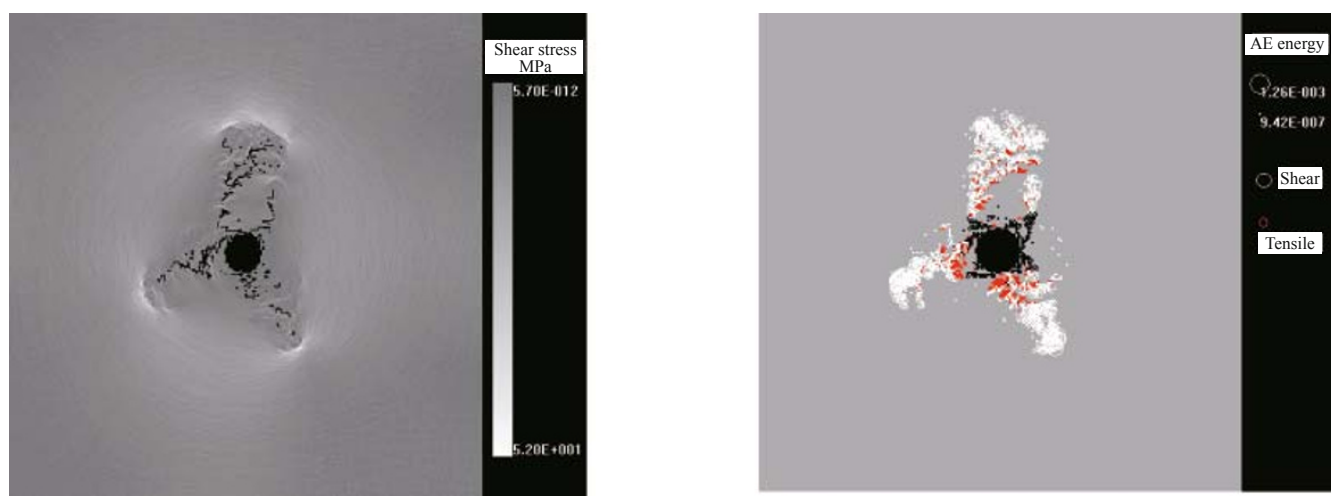

(d) Sub Step 30 of Step 9
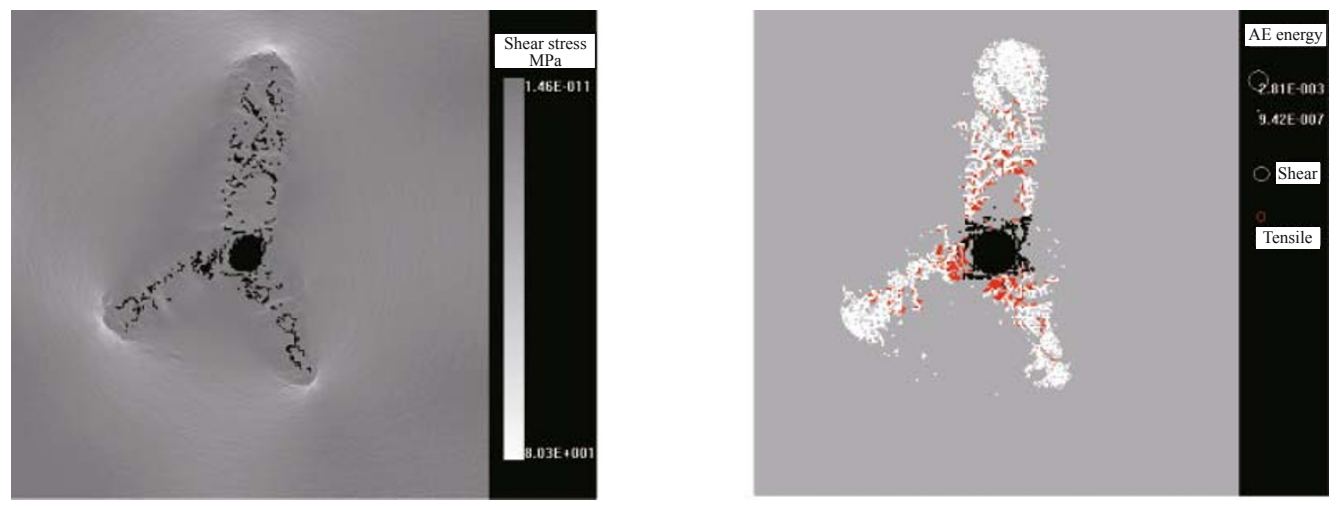

(e) Sub Step 40 of Step 9

Fig. 8 Damaged zones expand unstably in Step 9 (Left: Shear stress; Right: Acoustic emission) 


\section{2) Critical condition of borehole under non-hydrostatic loading}

There is also a critical condition of borehole excavation under non-hydrostatic loading. When the ratio of two in-situ stresses is $\sigma_{\mathrm{H} \text {, man }}: \sigma_{\mathrm{H} \text {, min }}=1.5: 1$, the critical condition is shown in Fig. 9. Because shear stress concentrates in the direction of $\sigma_{\mathrm{H} \text {, min }}$, shear acoustic emission is also focused in the direction of $\sigma_{\mathrm{H}, \min }$.

When the ratio of two in-situ stresses is $\sigma_{\mathrm{H} \text {,man }}: \sigma_{\mathrm{H} \text {, min }}$
$=3.5: 1$, the critical condition is shown in Fig. 10. Significantly, only tensile acoustic emissions occur in the direction of $\sigma_{\mathrm{H} \text {, max }}$ for tensile stress concentration damage. And for shear stress concentration damage the shear acoustic emissions occur in the direction of $\sigma_{\mathrm{H} \text {, min }}$, mingled with tensile acoustic emissions. As a result, four stress softening zones come into being around the borehole, including two symmetrical shear softening zones and two symmetrical tensile softening zones. This phenomenon is also observed in the cavern excavated in the fields where high differential stresses exist (Read, 2004).

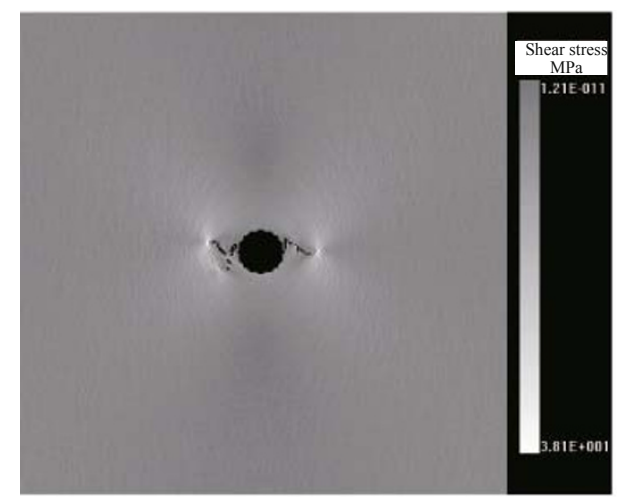

(a) Shear stress

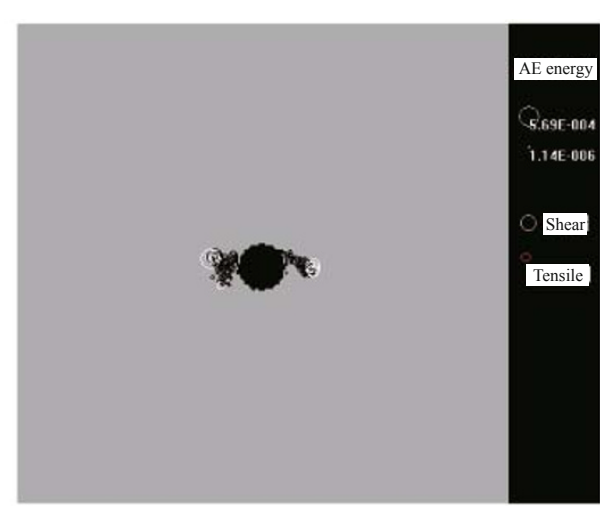

(b) Acoustic emission

Fig. 9 Critical condition of borehole in the case of $\sigma_{\mathrm{H}, \max }: \sigma_{\mathrm{H}, \min }=1.5: 1$

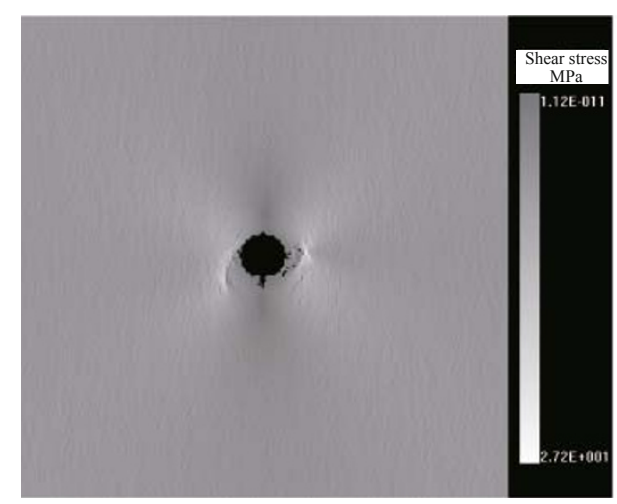

(a) Shear stress

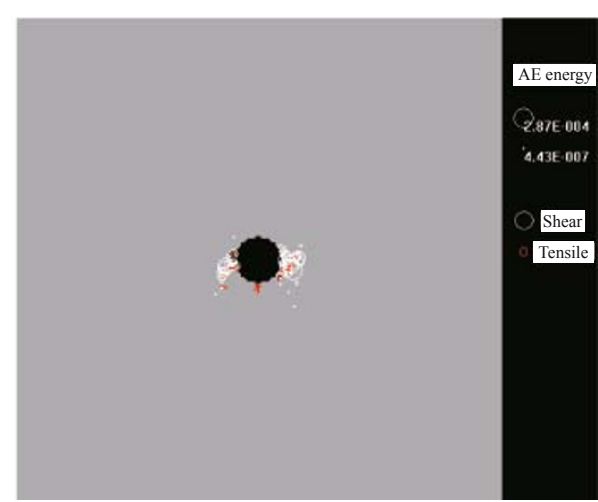

(b) Acoustic emission

Fig. 10 Critical condition of borehole in the case of $\sigma_{\mathrm{H}, \max }: \sigma_{\mathrm{H}, \min }=3.5: 1$

\section{True triaxial test}

To verify the result and conclusion of numerical simulation, true triaxial tests were carried out. Quadratic cement blocks, with dimensions of $30 \mathrm{~cm} \times 30 \mathrm{~cm} \times 30 \mathrm{~cm}$, were used. A borehole with a diameter of $5 \mathrm{~cm}$ was excavated beforehand in the cement block. The cement model rested in the test cell, shown in Fig. 11. Then hydraulic pressure was applied on boundaries in three mutually perpendicular directions. The test cell and loading sketch are shown in Fig. 12.

After the loading on the boundary exceeded the elastic limit load and continued to increase, macro fractures came into being on the borehole surface. Before the critical condition, the borehole kept stable although damaged zone emerged around the hole. Fig. 13 shows the damaged borehole before the critical condition.

Once the loading on boundary exceeded the ultimate bearing capacity of borehole, hydraulic pressure could not increase and the damaged zone expanded quickly and unstably. The borehole after the critical condition is shown in Fig. 14.

The laboratory experiments of true triaxial test verified the conclusion of numerical simulation. 


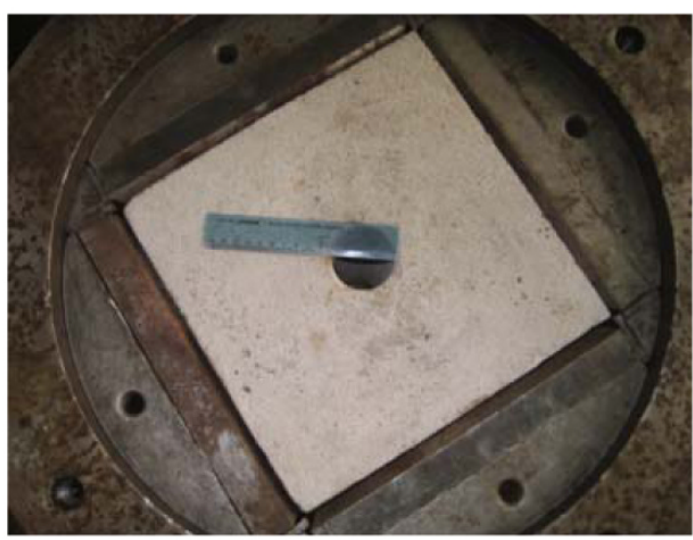

Fig. 11 Cement block with bore hole placed in test cell

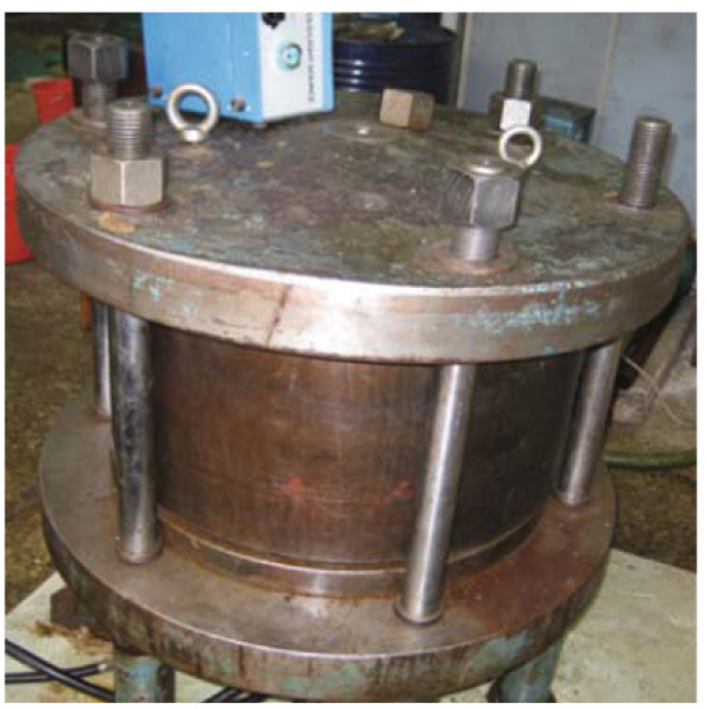

(a) Triaxial test cell

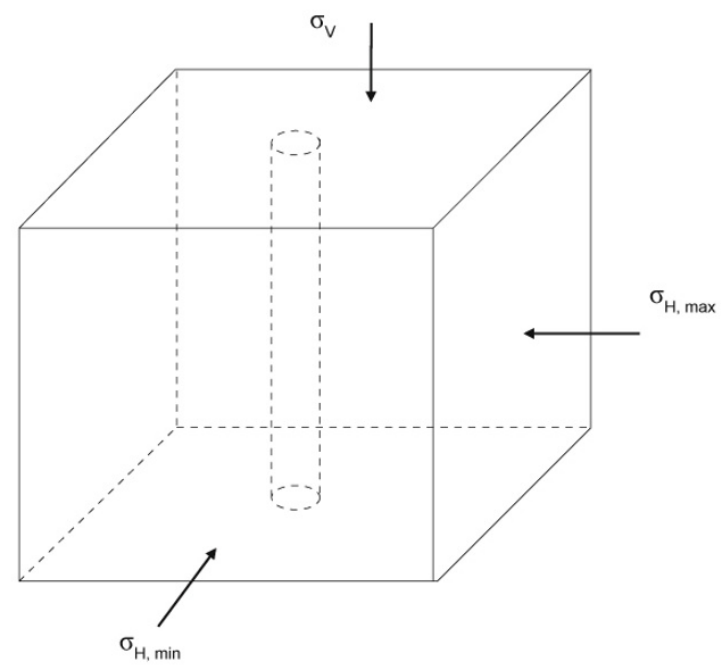

(b) Sketch of loading

Fig. 12 Loading in three mutually perpendicular directions

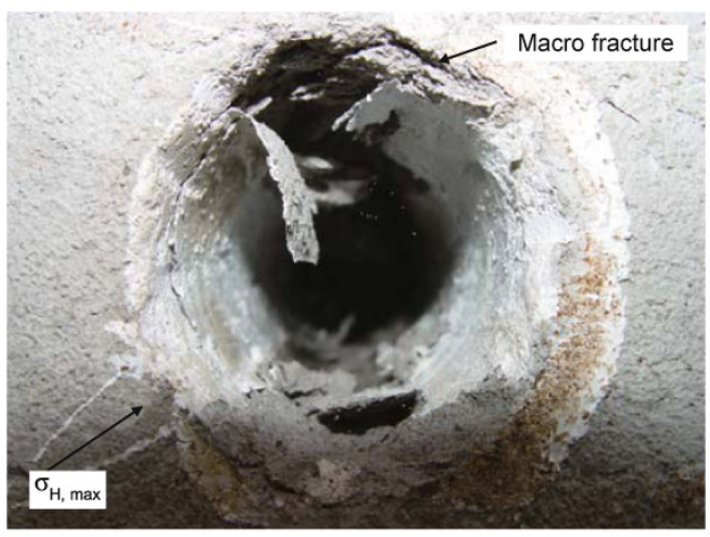

Fig. 13 Damaged zone around borehole before critical condition

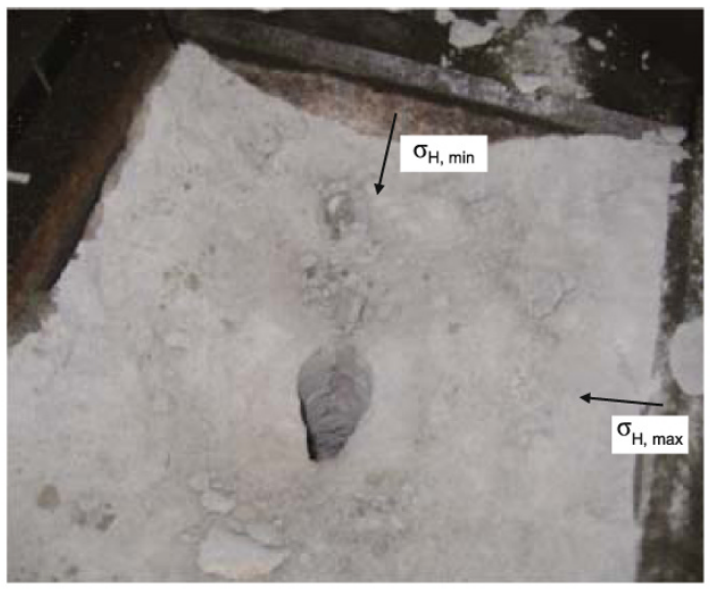

Fig. 14 Collapsed borehole after critical condition

\section{Discussion}

\subsection{Comparison with other research}

At present, borehole stability is usually studied and mud weight is calculated on the basis of keeping the surface of borehole elastic. This method may be reasonable during mud drilling. However, it under-estimates the borehole stability during air drilling without consideration of the plastic zone around the borehole. Although, an elasto-plastic analysis method is recommended (Carranza-Torres, 1998; CarranzaTorres and Fairhurst, 1999), the hypothesis of ideal plasticity leads to overestimation of borehole stability. So such traditional methods can not rationally explain the problems during air drilling. This paper presents a more practical and feasible method to study borehole stability during air drilling.

\subsection{Application prospect}

Air drilling has become an important technology in oil and gas industry. However, air drilling is confronted with such problems as prediction of borehole stability and losing stability after switching to drilling with mud. This paper may present solutions for the above problems.

1) Borehole can keep stable even if a damaged or plastic zone comes into being, provided that the damaged zone has not reached the critical damage condition. 
2) Because excavation damaged zone (EDZ) exists around the borehole during air drilling, the borehole easily loses stability after the drilling switches to using mud. So some counter-measures may be required such as wettability reversal or chemical grouting when switching to drilling with mud from air drilling.

\section{Conclusions}

This paper focuses on the existence of a critical condition of borehole excavation during air drilling. The following conclusions can be drawn from the numerical simulations and experiments.

1) As far as underground cavern or borehole excavation is concerned, a critical damage condition exists. If the damaged zone around the borehole outranges the critical condition, the underground cavern or bore-hole will lose stability.

2) It is reasonable to analyze borehole stability based on the critical condition during air drilling.

3) The excavation damaged zone around the borehole usually comes into being during air drilling. In the EDZ, micro-cracks develop and combine into macro-fractures, resulting in remarkable change in physical and mechanical properties of the surrounding rock. So the EDZ will easily collapse after switching to mud drilling from air drilling.

4) Finally, it is worthwhile to notice that analytical results of the critical condition depend on such factors as stress path, rock strength criterion, and scale effect. Further studies based on numerical simulation and experimental tests are needed.

\section{Acknowledgements}

The author thanks Professor Chun'an Tang for his valuable advice and suggestions.

\section{References}

Alcott J M, Kaiser P K and Simser B P. Use of microseismic source parameters for rockburst hazard assessment. Pure and Appllied Geophysics. 1998. 153: 41-65

Cai M, Kaiser P K, Morioka H, et al. FLAC/PFC coupled numerical simulation of $\mathrm{AE}$ in large-scale underground excavations. International Journal of Rock Mechanics and Mining Sciences. 2007. 44: $550-564$

Carranza-Torres $\mathrm{C}$ and Fairhurst C. The elasto-plastic response of underground excavations in rock masses that satisfy the Hoek-Brown failure criterion. International Journal of Rock Mechanics Sciences. 1999. 36(6): 777-809

Carranza-Torres C. Self-similarity analysis of the elasto-plastic response of underground openings in rock and effects of practical variables. Ph.D Thesis. University of Minnesota. 1998

Chen W F. Limit Analysis and Soil Plasticity. Amsterdam: Elsevier. 1975

Costin L S. Damage mechanics in the post failure regime. Mechanics of Materials. 1985. 4: 149-160

Drucker D C and Prager W. Soil mechanics and plastic analysis on limit design. Quarterly of Applied Mathematics. 1952. 10: 157-65

Durand A F, Vargas Jr E A and Vaz L E. Applications of numerical limit analysis (NLA) to stability problems of rock and soil masses. International Journal of Rock Mechanics and Mining Sciences. 2006. 43(3): 408-425

Eberhardt E, Stead D and Stimpson B. Quantifying progressive pre- peak brittle fracture damage in rock during uniaxial compression. International Journal of Rock Mechanics and Mining Sciences. 1999. 36: 361-380

Hardy H R. Acoustic emission/microseismic activity. Vol.1, Principles, Techniques, and Geotechnical Applications. Rotterdam: Balkema A A. 2003

Hommand-Etienne F, Hoxha D and Shao J F. A continuum damage constitutive law for brittle rocks. Computers and Geotechnics. 1998. 22(2): 135-153

Jaeger J C and Cook N G W. Fundamentals of Rock Mechanics. London: John Wiley and Sons. 1976

Martin C D and Chandler N A. The progressive failure of Lac du Bonnet granite. International Journal of Rock Mechanics and Mining Science. 1994. 31: 643-659

Read R S. 20 years of excavation response: studies at AECL's underground research laboratory. International Journal of Rock Mechanics and Mining Sciences. 2004. 41: 1251-1275

Salençon J. Contraction Quasi-Statique D'une Cavite a Symetrie Spherique Ou Cylindrique Dans Un Milieu Elastoplastique. Annales Des Ponts Et Chaussees. 1969. 4: 231-236

Sammis C G and Ashby M F. The failure of brittle porous solids under compressive stress state. Acta Metal. 1986. 34(3): 511-526

Singh U K and Digby P J. A continuum damage model for simulation of the progressive failure of brittle rocks. International Journal of Solids and Structures. 1989. 25(6): 647-663

Steif P S. Crack extension under compressive loading. Engineering Fracture Mechanics. 1984. 20(3): 463-473

Tang C A and Kaiser P K. Numerical simulation of cumulative damage and seismic energy release during brittle rock failure-Part I Fundamentals. International Journal of Rock Mechanics and Mining Sciences. 1998a. 35(2): 113-121

Tang C A and Kaiser P K. Numerical simulation of damage accumulation and seismic energy release during brittle rock failure-Part II: Rib pillar collapse. International Journal of Rock Mechanics and Mining Sciences. 1998b. 35(2):123-134

Tang C A, Liu H, Lee P K K, et al. Numerical studies of the influence of microstructure on rock failure in uniaxial compression-Part I: Effect of heterogeneity. International Journal of Rock Mechanics and Mining Sciences. 2000. 37(4): 555-569

Tang C A. Numerical simulation on progressive failure leading to collapse and associated seismicity. International Journal of Rock Mechanics and Mining Sciences. 1997. 34(2): 249-61.

Tsang C F, Bernier F, and Davies C. Geohydromechanical processes in the excavation damaged zone in crystalline rock, rock salt, and indurated and plastic clays-in the context of radioactive waste disposal. International Journal of Rock Mechanics and Mining Sciences. 2005. 42(1): 109-125

Wang R, Xiong Z H and Huang W B. Fundamentals of Plastic Mechanics. Beijing: Science Press. 1982 (in Chinese)

Wang S H, Liu J X and Tang C A. Stability analysis of a large-span, deep tunnel. International Journal of Rock Mechanics and Mining Sciences. 2004. 41(Supplement 1): 870-875

Wawersik W R and Brace W F. Post-failure behavior of a granite and diabase. Rock Mechanics. 1971. 3: 61-68

Xu B Y and Liu X S. Application of Elasto-plastic Mechanics. Beijing: Tsinghua University Press. 1995 (in Chinese)

Zhang H Q, Zhao Z Y, Tang C A, et al. Numerical study of shear behavior of intermittent rock joints with different geometrical parameters. International Journal of Rock Mechanics \& Mining Sciences. 2006. 43(5): 802-816

Zhu W C and Tang C A. Numerical simulation of Brazilian disk rock failure under static and dynamic loading. International Journal of Rock Mechanics \& Mining Sciences. 2006. 43(2): 236-252

(Edited by Sun Yanhua) 